\title{
Anti-proliferative and antioxidant properties of rosemary Rosmarinus officinalis
}

\author{
SUSAN CHEUNG and JOSEPH TAI
}

\begin{abstract}
Department of Pathology and Pediatrics, Center for Complementary Medicine Research, Child and Family Research Institute, British Columbia Children's and Women's Health Center, University of British Columbia, Canada
\end{abstract}

Received October 10, 2006; Accepted December 27, 2006

\begin{abstract}
Constituents in rosemary have shown a variety of pharmacological activities for cancer chemoprevention and therapy in in vitro and in vivo models. In order to further explore the chemopreventive properties of crude extracts of rosemary (Rosmarinus officinalis L), we studied its antiproliferative property on several human cancer cell lines and its antioxidant and anti-inflammatory properties in vitro in a mouse RAW 264.7 macrophage/monocyte cell line. Our study shows that crude ethanolic rosemary extract (RO) has differential anti-proliferative effects on human leukemia and breast carcinoma cells. The $50 \%$ inhibitory concentration (IC50) was estimated at 1/700, 1/400, 1/150 and 1/500 dilutions, for the HL60, K562, MCF7 and MDA-MB-468 cells, respectively. Non-cytotoxic concentrations of RO at 1/1000 dilution minimally induced HL60 cell differentiation into granulocyte lineage at $9.5 \pm 2.2 \%$ compared to $2.8 \pm 0.8 \%$ in the untreated control $(\mathrm{p}<0.001)$, and did not induce HL60 cell differentiation into monocyte/macrophage lineage. The 6-hydroxy-2,5,7,8-tetramethyl-chroman-2-carboxylic acid (Trolox) equivalent antioxidant capacity assay showed that RO has substantial antioxidant activity with RO at 1/10 and 1/5 dilutions having 8.1 and $12.6 \mu \mathrm{M}$ Trolox equivalents, respectively. RO at non-cytotoxic $1 / 2000$ and $1 / 1000$ dilutions did not affect nitric oxide (NO) production by non-stimulated RAW 264.7 cells. However, at the same dilutions RO significantly reduced NO production by lipopolysaccharide (LPS)activated cells in a dose-dependent manner from $32.6 \pm 2.3 \mu \mathrm{M}$ in the LPS-activated cells to $19.2 \pm 2.2 \mu \mathrm{M}(\mathrm{p}<0.01)$, and $7.7 \pm 1.2 \mu \mathrm{M}(\mathrm{p}<0.001)$, respectively. RT-PCR analyses showed that RAW 264.7 cells treated with $1 / 1000$ and $1 / 500$ dilutions for $5 \mathrm{~h}$ did not affect TNF $\alpha$, IL-1ß, iNOS and COX-2 mRNA
\end{abstract}

Correspondence to: Dr Joseph Tai, Child and Family Research Institute, SHY L306, 4480 Oak Street, Vancouver, British Columbia V6H 3N4, Canada

E-mail: jtai@interchange.ubc.ca

Key words: herbal extract, Rosmarinus officinalis, cytotoxicity, antiinflammatory, antioxidant, tumor cell lines, gene expression expression in these cells when compared to the untreated controls, nor did the 1/1000 dilution of RO affect TNF $\alpha$, IL- 13 , iNOS and COX-2 mRNA expression in the LPS-activated cells. At $1 / 500$ dilution, RO significantly reduced IL-1B $(\mathrm{p}<0.01)$ and COX-2 $(\mathrm{p}<0.05)$ mRNA expression and nonsignificantly reduced $\mathrm{TNF} \alpha$ and iNOS mRNA expression in the LPS-activated cells. In view of the chemopreventive potentials, further studies are needed to explore other biological properties of this popular spice used by many cultures in the world.

\section{Introduction}

Dietary phytochemicals are a rich source of flavonoids shown to have chemopreventive properties. Rosemary carnosol, green tea epigallocatechin gallate, tumeric, and curcumin are among the well-studied dietary phytochemicals in literature. The chemical constituents of rosemary (Rosmarinus officinalis L, family Lamiaceae) include flavonoids such as carnosol, carnosic and rosmarinic acid, and volatile oils $(1,2)$. Carnosol and carnosic acid constitute $3.8-4.6 \%$ of the material extracted from rosemary, and they are among the many constituents in rosemary that show pharmacological properties (3). Carnosol has shown a number of in vitro and in vivo biological activities including strong antioxidant activity by nitric oxide inhibition assay $(4,5)$, anti-mutagenic effects in the Ames assay (6), inhibition of DNA adduct formation in human bronchial cells (7), in vitro anti-metastasis in B16/F10 mouse melanoma cells (8), and in vivo inhibition of tumorigenesis in rodent skin (3), mammary (9), and gut (10) models. Constituents in the methanol extract of rosemary other than carnosol, and carnosic and rosmarinic acid are thought to be responsible for the inhibition of P-glycoprotein activity in a multidrug-resistant MCF7 cell line (11). In addition, the water insoluble fraction of rosemary extract increased nerve growth factor production in T98G human glioblastoma cells. This activity could be attributed to carnosic acid (12). These results suggest that constituents of rosemary other than carnosol may have pharmacological effects for cancer chemoprevention and therapy. In order to further explore the chemopreventive properties of crude extracts of rosemary, we studied its antioxidant and antiinflammatory properties in an in vitro mouse RAW 264.7 macrophages system, and its anti-proliferative activity on several human tumor cell lines. 


\section{Materials and methods}

Plant material and preparation of the extract. Two different lots of Rosmarinus officinalis dry leaves were purchased from the herbs and spice section in a grocery store in Vancouver. Voucher samples are stored in the authors' laboratory. The dry leaves were pulverized into fine powder in a blender. For cell culture studies, $1 \mathrm{~g}$ of the powder was extracted with $10 \mathrm{ml} 70 \%$ ethanol for $2 \mathrm{~h}$ at $55^{\circ} \mathrm{C}$. The suspension was centrifuged at $5,000 \mathrm{x}$ g for $10 \mathrm{~min}$ and the supernatant [rosemary extract (RO)] yielded a stock with an estimated $13.4 \mathrm{mg}$ dry material in $1 \mathrm{ml}$ of the RO extract. Varying dilutions of this extract were used for cell culture and other assay studies.

Chemicals and reagents. Unless specified, all chemicals were of reagent grade purchased from Sigma-Aldrich of Canada (Oakville, Ontario, Canada). Camptothecin (CAM, cat. no. C9911) and paclitaxel (PTX, cat. no. T7402) were dissolved in dimethyl sulfoxide (DMSO) as $1 \mathrm{mM}$ stock and further diluted to the desired concentrations with a culture medium. 6-Hydroxy-2,5,7,8-tetramethyl-chroman-2-carboxylic acid (Trolox, cat. no. 39,192-1), 2,2'-azinobis[3-ethylbenzothiazoline-6-sulfonic acid] (ABTS, cat. no. A1888), lipopolysaccharide (LPS cat. no. L2630), 4-beta-phorbol-12-myristate13-acetate (PMA, cat. no. P8139), dimethyl formamide (DMF), nitro-blue tetrazolium (NBT, cat. no. N6876).

High performance liquid chromatography (HPLC) profile. A $70 \%$ ethanol extract of rosemary was prepared according to the prescribed method. British Columbia's Institute of Technology Forensic Science Center performed the HPLC fingerprint. An injection of $5 \mu 1$ of this extract was used for chromatographic analysis. HPLC analysis was carried out using an Agilent 1100 HPLC equipped with a binary pump, autosampler, thermostatted column compartment, and a diode array detector. The mobile phase used was: Solvent A $\left(\mathrm{H}_{2} \mathrm{O} ; 0.1 \%\right.$ formic acid) and Solvent B (Acetonitrile; $0.1 \%$ formic acid). The flow rate was $1 \mathrm{ml} / \mathrm{min}$ with a column temperature of $20^{\circ} \mathrm{C}$ for analysis in a Zorbax SB-C18 4.6x150 mm with a 3.5-um particle size column (Agilent Technologies Inc. pn 863953-902). It was found that $210 \mathrm{~nm}$ provided the best representation of compounds present in the extract. The chromatograms for the ethanol extracts were background subtracted using the ethanol water mixture used for the extraction process.

Antioxidant activity - Trolox equivalent antioxidant capacity (TEAC). The test is based on the reduction of the ABTS radical cation by antioxidants $(13,14)$. Trolox $(25 \mathrm{mM})$ was prepared in ethanol for use as a stock standard. Fresh working standards of $0.5,1$ and $2 \mathrm{mM}$ were prepared by dilution with distilled water. The stock solution of the ABTS radical cation was prepared by mixing ABTS $(7 \mathrm{mM})$ with $2.45 \mathrm{mM}$ potassium persulfate in water. The mixture was kept for $12-24 \mathrm{~h}$ at ambient temperature in the dark until the reaction was complete and the absorbance became stable. In order to prepare an $\mathrm{ABTS}^{\bullet+}$ working solution, the $\mathrm{ABTS}^{\bullet+}$ stock solution was diluted with water to an absorbance of $0.700 \pm 0.02$ at $734 \mathrm{~nm}$. For the photometric assay, $1 \mathrm{ml} \mathrm{ABTS}^{\bullet+}$ working solution and $10 \mu 1$ Trolox standards or test solution were mixed for $45 \mathrm{sec}$ and measured immediately after $1 \mathrm{~min}$ at $734 \mathrm{~nm}$. The antioxidant activity of the test substances was calculated by determining the decrease in absorbance using the following equation: \% antioxidant activity $=\left\{\left(\mathrm{E}\left[\mathrm{ABTS}^{\circ+}-\mathrm{E}\right.\right.\right.$ [standard $\left.]\right) /$ E $\left.\left[\mathrm{ABTS}^{\cdot+}\right]\right\} \times 100$. The Trolox equivalents were estimated by linear interpolation of the antioxidant activity from the Trolox standards.

Cell lines and culture conditions. Human mammary adenocarcinoma MCF7 and MDA-MB-468, human promyelomonocytic HL60 cells, and the murine RAW264.7 macrophage/monocyte cell line were purchased from the American Type Culture Collection (Rockville, MD, USA). The human leukemia cell line, K562, was a gift from Dr A.J. Tingle, at British Columbia's Research Institute for Children's and Women's Health. The MDA-MB-468 cells were cultured in L15 medium, the HL60 cells were cultured in Iscove's medium, and the MCF7, K562 and RAW264.7 cells were cultured in Dulbecco's minimal essential (DMEM) medium supplemented with $10 \%$ fetal bovine serum, 2 mM L-glutamine, and $50 \mu \mathrm{g} / \mathrm{ml}$ gentamycin. The cultures were maintained in a humidified $5 \% \mathrm{CO}_{2}$ incubator at $37^{\circ} \mathrm{C}$ except for MDAMB-468, which was maintained in an incubator with air. The cells were sub-cultured every 3-4 days to maintain logarithmic growth and were allowed to grow for $24 \mathrm{~h}$ before use.

Cell proliferation assay. For testing, the tumor cells were cultured in 96-well plates. The starting cell numbers were $2.5 \times 10^{4}$ cells per well for K562, and $10^{4}$ cells for MCF7 and MDA-MB-468. For the HL60 cells, the starting cell number was $10^{5}$ cells per well in 24-well plates in order to coordinate with the cell differentiation assay. After the cells stabilized overnight, triplicate (duplicate for HL60) samples of cells were treated with a culture medium containing different dilutions of RO extract. The chemotherapeutic agents, CAM or PTX, were included in the assays as the positive controls. Cell counting was set at 2 days for K562, 3 for HL60, 4 for MCF7 and 5 for MDA-MB-468. Cell numbers were determined by hemocytometer counting and viability was assessed by the trypan blue dye exclusion test. Cell counts in the samples treated with the test compounds were normalized to a percentage of the control, and the means and standard errors (SEM) were calculated from at least three independent experiments (15). The fifty percent inhibitory concentration (IC50) of the anti-proliferative effects was determined by linear regression estimation.

\section{Cell differentiation assay.}

Differentiation into granulocyte lineage by NBT reduction assay. Duplicate $50 \mu 1$ aliquots of HL60 cells treated with the different dilutions of RO were incubated with an equal volume of phenol red free RPMI medium containing $200 \mathrm{ng} / \mathrm{ml}$ PMA and $0.2 \% \mathrm{NBT}$ at $37^{\circ} \mathrm{C}$ for $45 \mathrm{~min}$ in a flat bottomed 96-well tissue culture plate. For each preparation, 200 cells were examined microscopically to determine the proportion of cells containing blue-black formazan granules, indicative of the ability of HL60 to generate superoxide anion during an induced respiratory burst. In addition, cytocentrifuge smears of the control and treated cells were stained with Giemsa and 
analyzed by microscopy to allow the observation of granulocytic features i.e. a multilobular nucleus, and prominent cellular indentation. The positive control of differentiation to the granulocytes was achieved by the addition of $100 \mathrm{mM}$ DMF. The results are expressed as a percentage of the NBTpositive cells (16).

Differentiation into macrophage/monocyte lineage by nonspecific esterase (NSE) activity assay. Standard NSE staining (17) was performed on duplicate microscope slides from samples prepared by a cytocentrifuge. Two hundred cells were examined under a microscope in order to determine the proportion of NSE-positive cells (a brownish red cytoplasm). Cells treated with 25 or $50 \mathrm{ng} / \mathrm{ml}$ PMA were used as the positive control.

Inhibition of LPS-activated nitric oxide (NO) production by RAW264.7 cells. RAW 264.7 cells were cultured in 24-well plates $\left(1 \times 10^{6} \mathrm{cells} / \mathrm{ml} /\right.$ well, NUNC culture plates) with phenol red free RPMI medium supplemented with 5\% FBS. On the following day varying dilutions of RO extract were added to the RAW 264.7 cells alone, or in combination with $1 \mu \mathrm{g} / \mathrm{ml}$ LPS, in a fresh medium. After 48 -h incubation at $37^{\circ} \mathrm{C}$, the amount of NO released into the culture supernatant was determined with Griess reagent and compared to a sodium nitrite standard of known concentration by absorbance at $550 \mathrm{~nm}$. Cell proliferation and viability at the end of the experiment were determined by staining the cells with neutral red dye at $50 \mu \mathrm{g} / \mathrm{ml}$ for $1 \mathrm{~h}(18,19)$.

$R T$-PCR. RAW 264.7 cells $(3 \mathrm{ml})$ at $2 \times 10^{6}$ cells $/ \mathrm{ml}$, DMEM supplemented with $10 \%$ FBS, 2 mM L-glutamine and $50 \mu \mathrm{g} / \mathrm{ml}$ gentamycin, were cultured in each of the 6-well culture plates in a $37^{\circ} \mathrm{C}, 5 \% \mathrm{CO}_{2}$ humidified incubator. After $48 \mathrm{~h}$, the cells were treated with $1 / 1000$ and 1/500 dilutions of RO alone or in combination with $1 \mu \mathrm{g} / \mathrm{ml}$ LPS in a fresh culture medium. Five hours later, RNA was isolated with TRIzol reagent (Invitrogen, Burlington, Ontario, Canada). Total RNA $(1 \mu \mathrm{g})$ was reverse transcribed into cDNA using Superscript II reverse transcriptase according to the manufacturer's protocol (no. 18064 , Invitrogen) at $42^{\circ} \mathrm{C}$ for $50 \mathrm{~min}$. PCR was performed with $100 \mathrm{ng}$ of the cDNA template in $25 \mu \mathrm{l}$ volumes containing $1 \mathrm{x}$ reaction buffer, $1.5 \mathrm{mM} \mathrm{MgCl}{ }^{2}, 200 \mu \mathrm{M}$ dNTPs, 0.5 U Platinum Tag DNA polymerase (no. 10966, Invitrogen), and $0.4 \mu \mathrm{M}$ of the following primer pairs: IL1- $\beta$, 5'- TTG ACG GAC CCC AAA AGA TG -3' and 5'- AGA AGG TGC TCA TGT CCT CA -3'; TNF- $\alpha, 5^{\prime}$ - TCT CAT CAG TTC TAT GGC CC -3' and 5'- GGG AGT AGA CAA GGT ACA AC -3'; iNOS, 5'- CCC TTC CGA AGT TTC TGG CAG CAG -3' and 5'- GGC TGT CAG AGA GCC TCG TGG CTT TGG -3'; COX-2, 5'- CCC CCA CAG TCA AAG ACA CT -3' and 5'- CCC CAA AGA TAG CAT CTG GA -3' and G3PDH, 5'- TGA AGG TCG GTG TGA ACG GAT TTG GC - 3 ' and 5'- CAT GTA GGC CAT GAG GTC CAC CAC -3 (20-22).

After an initial denaturation for $2 \mathrm{~min}$ at $94^{\circ} \mathrm{C}, 28-35$ cycles of amplifications $\left(55^{\circ} \mathrm{C}\right.$ for $40 \mathrm{sec}, 72^{\circ} \mathrm{C}$ for $1 \mathrm{~min}$, and $94^{\circ} \mathrm{C}$ for $1 \mathrm{~min}$ ) were performed followed by a 7 -min extension at $68^{\circ} \mathrm{C}$ in a DNA Thermal Cycler 480 (PerkinElmer, Norwalk, CT, USA). A $10 \mu 1$ aliquot from each PCR reaction was electrophoresed in $2 \%$ agarose gels and visualized by ethidium bromide staining. The PCR products of mRNA expression were semi-quantitatively measured using the GelDoc system with a CCD camera (BioRad, Molecular Analyst), and the relative IL-1ß, TNF- $\alpha$, iNOS and COX-2 signals were normalized against the housekeeping gene G3PDH. Data were expressed as the ratio of G3PDH.

Statistical analysis. Data are presented as the mean \pm SEM from at least three independent experiments. The Student's two-tailed unpaired t-test was used in a statistical comparison of the two groups. Differences were considered significant when $\mathrm{p}<0.05$

\section{Results}

HPLC profile. HPLC spectra at 210, 250, 280 and $300 \mathrm{~nm}$ showed that numerous compounds are present in the RO extract. Fig. 1 shows a HPLC spectrum at $210 \mathrm{~nm}$ with the most spectral peaks.

Anti-proliferative activity. Fig. 2 shows that the RO extract caused differential anti-proliferative activity on the breast and leukemia cell lines tested, with HL60 being the most susceptible, and MCF7 the most resistant. IC50 was estimated at 1/700, 1/400, 1/150 and 1/500, for the HL60, K562, MCF7 and MDA-MB-468 cells, respectively.

HL60 cell differentiation. Fig. 3 shows that the RO extract at $1 / 1000$ dilution induced $9.5 \pm 2.2 \%$ of HL60 cell differentiation along granulocyte lineage with $\mathrm{p}<0.01$ compared to the untreated control at $2.8 \pm 0.8 \%$. Non-cytotoxic concentrations of RO had no effect on the monocyte/macrophage differentiation of the HL60 cells.

Antioxidant activities. Cell free ABTS OH radical scavenging assay showed that the RO extract has substantial antioxidant activity with $1 / 10$ and $1 / 5$ dilutions of the RO showing 8.1 and $12.6 \mu \mathrm{M}$ of the Trolox equivalents, respectively (Fig. 4A). Fig. 4B shows the effects of RO on NO production by the LPS-activated RAW 264.7 cells. The basal level of NO represented by the nitrite concentration in the culture medium was $<2 \mu \mathrm{M}$. The addition of non-cytotoxic concentrations of RO at $1 / 2000$ and $1 / 1000$ dilutions to non-stimulated RAW 264.7 cells did not affect the NO production by these cells. However, RO at these concentrations significantly inhibited NO production by the LPS-activated RAW 264.7 cells in a dose-dependent manner. NO in the culture supernatant was reduced from $32.6 \pm 2.3 \mu \mathrm{M}$ in the LPS-activated cells to $19.2 \pm 2.2 \mu \mathrm{M}(\mathrm{p}<0.01)$ and $7.7 \pm 1.2 \mu \mathrm{M}(\mathrm{p}<0.001)$, with the addition of $1 / 2000$ and $1 / 1000$ dilutions of RO, respectively. The RO extract at these dilutions was not cytotoxic to the RAW 264.7 cells as the cell viability assay by neutral red incorporation was $>80 \%$ when compared to the untreated control.

$R T$-PCR Fig. 5 shows that treatment with $1 / 1000$ and $1 / 500$ dilutions of RO extract for $5 \mathrm{~h}$ did not affect TNF $\alpha$, IL-1ß, iNOS and COX-2 mRNA expression in RAW 264.7 cells when compared to the untreated controls, nor did treatment 




Figure 1. High performance liquid chromatography profile of $70 \%$ ethanol extract of Rosmarinus officinalis at $210 \mathrm{~nm}$.

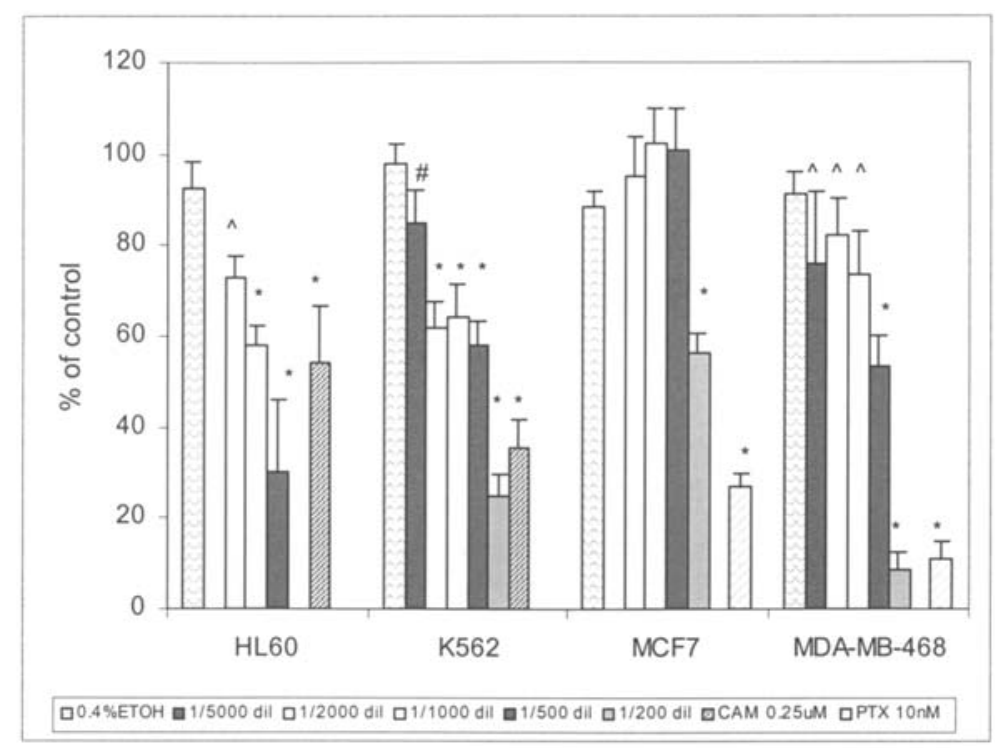

Figure 2. Effects of the rosemary ethanol extract on the proliferation of HL60, K562, MCF7 and MDA-MB-468 cells. The conditions for cell culture are described in 'Materials and methods'. Cell proliferation was assessed by the hemocytometer counting of viable cells with the trypan blue exclusion method. The results are presented as the means \pm SEM of at least three independent experiments normalized to the control. Dilutions of rosemary ethanol crude extract $(1 / 5000,1 / 2000,1 / 1000,1 / 500$ and 1/200 dil) were added to the cell cultures. ETOH (ethanol) (0.4\%), CAM (camptothecin) $0.25 \mu \mathrm{M}$ and PTX (paclitaxel) $10 \mathrm{nM}$ were the negative and positive controls for the cell proliferation assay. $\mathrm{t}$-test: ${ }^{\wedge} \mathrm{p}<0.05,{ }^{\sharp} \mathrm{p}<0.01,{ }^{*} \mathrm{p}<0.001$ compared to the untreated control.

with $1 / 1000$ dilution of RO affect TNF $\alpha$, IL-1ß, iNOS and COX-2 mRNA expression in the LPS-activated cells. At $1 / 500$ dilution, RO significantly reduced IL-1ß $(\mathrm{p}<0.01)$ and COX-2 ( $\mathrm{p}<0.05)$ mRNA expression, but non-significantly reduced TNF $\alpha$ and iNOS mRNA expression in the LPSactivated cells.

\section{Discussion}

Rosemary crude extract and its constituents carnosol and carnosic acid have been reported to show chemopreventive benefits in in vivo anti-tumorigenesis studies, with the activation of phase I and phase II detoxifying enzymes being 

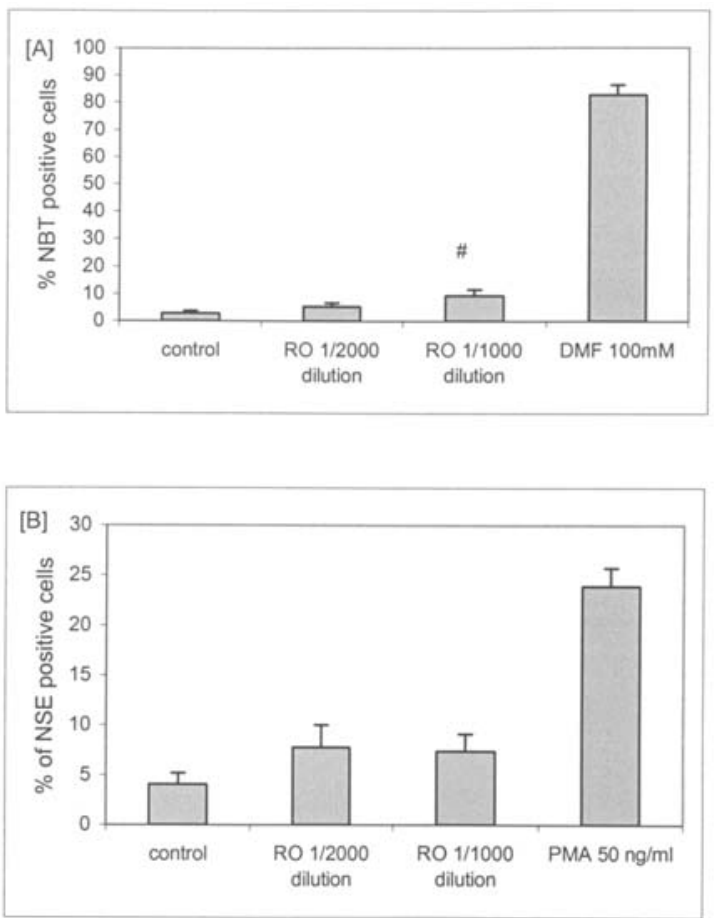

Figure 3. Effects of rosemary extracts (RO) on the differentiation of HL60 leukemia cells. HL60 cells $(1 \mathrm{ml})$ at $1 \times 10^{5} / \mathrm{ml}$ were transferred to each $24-$ well culture plate. After overnight culture, fresh media containing RO extracts at $1 / 500,1 / 1000$ or $1 / 2000$ dilutions were added, and the cells were cultured for an additional 3 days for nitro-blue tetrazolium (NBT), and non-specific esterase (NSE) assay. Panel (A) shows the effects of RO on HL60 cell differentiation along the granulocyte lineage by the presence of NBTpositive cells. Panel (B) shows the effects of RO on HL60 cell differentiation along the macrophage/monocyte lineage by the presence of NSEpositive cells. ETOH (0.4\%) is the vehicle control. 4-Beta-phorbol-12myristate-13-acetate (PMA) $(50 \mathrm{ng} / \mathrm{ml})$ and dimethyl formamide (DMF) $(100 \mathrm{mM})$ are inducers of macrophage/monocyte, and granulocyte differentiation, respectively. ${ }^{\#} \mathrm{p}<0.05$ when compared to the untreated control.
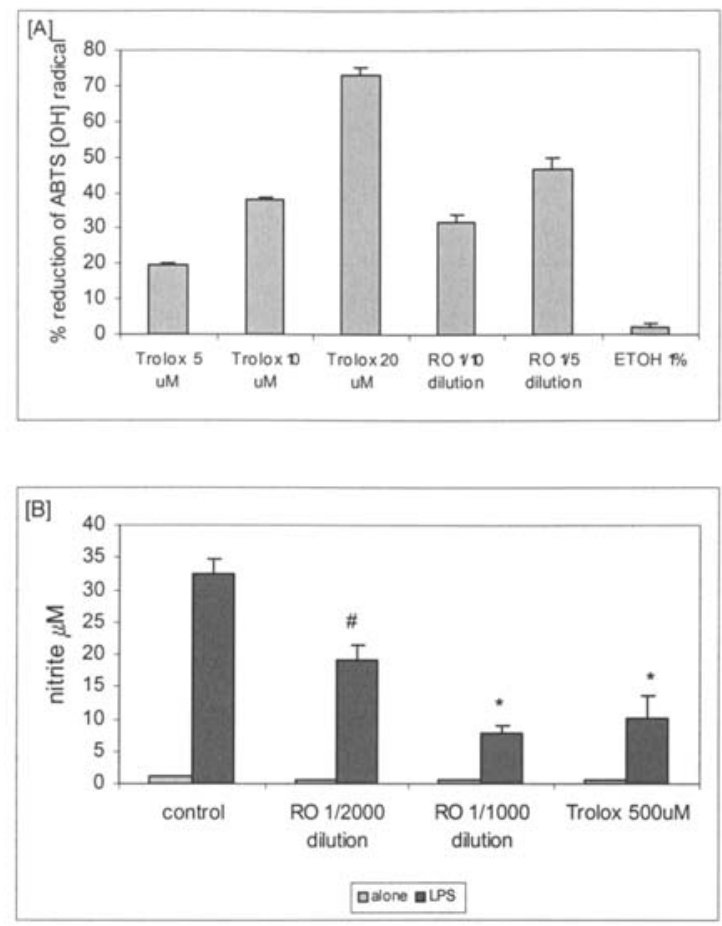

Figure 4. Antioxidant properties of the rosemary ethanol extract (RO). Panel (A) shows the antioxidant activity of RO measured by 6-Hydoxy-2,5,7,8-tetramethyl-chromasn-2-carboxilic acid (Trolox) equivalent antioxidant capacity assay. The reduction of the ABTS OH radical by RO was compared to Trolox, a chemical with potent antioxidant activity by this assay. Panel (B) shows the effects of RO on nitric oxide (NO) production in the mouse macrophage RAW 264.7 cell line. RAW264.7 cells were treated with $1 / 2000$ or $1 / 1000$ dilutions of RO alone or in combination with lipopolysaccharide (LPS) $(1 \mu \mathrm{g} / \mathrm{ml})$ for $48 \mathrm{~h}$. The culture supernatants were subsequently collected and analyzed for NO content represented as nitrite levels with Griess reagent. Data represent the means \pm SEM of at least six independent experiments. RO significantly attenuated NO production in a concentration-dependent manner in the LPSactivated RAW 264.7 cells. Student's t-test: " $\mathrm{p}<0.01$ and " $\mathrm{p}<0.001$ compared to the LPS-stimulated samples.
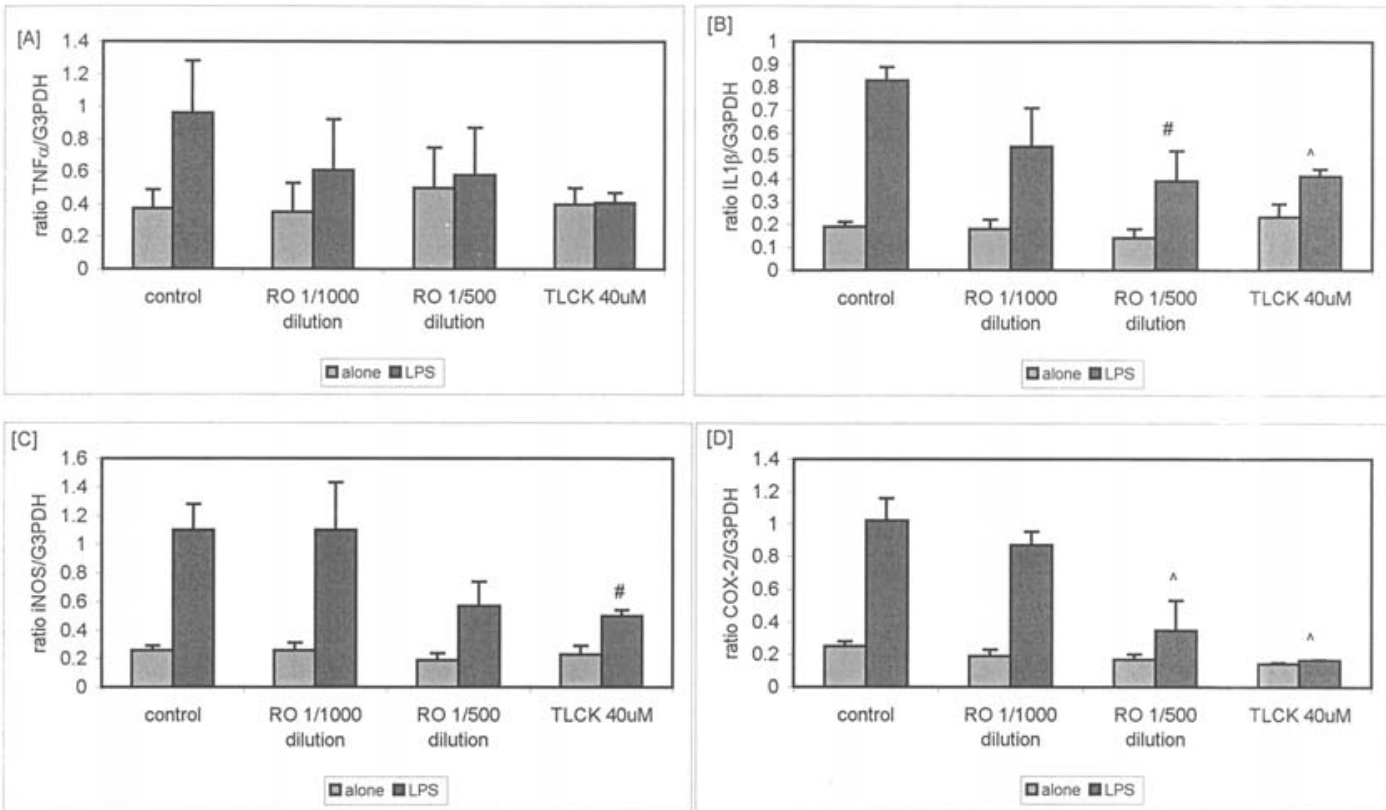

Figure 5. RT-PCR analyses of the effects of rosemary ethanol extract (RO) on the mRNA expression of (A) TNF- $\alpha$, (B) IL1- $\beta$, (C) iNOS, and (D) COX-2 in RAW 264.7 cells stimulated with lipopolysaccharide (LPS) $(1 \mathrm{mg} / \mathrm{ml})$ for $5 \mathrm{~h}$. Data represent the densitometric analyses from gel photographs of the gene product normalized to that of the housekeeping gene, G3PDH. Results are the means \pm SEM of more than three independent experiments. TLCK (40 $\mu \mathrm{M})$ is an inhibitor of iNOS mRNA transcription via the NF-kB pathway. ${ }^{\wedge} \mathrm{p}<0.05$ and ${ }^{\#} \mathrm{p}<0.01$, compared to the LPS-stimulated samples by the t-test. 
implicated as the mechanisms of action $(7,9,23)$. In vitro studies have shown that purified carnosol can interfere with tumor cell metastasis, chemtotaxis and attachment (8). There are several reported studies in the literature on the antiproliferative activities of rosemary or its constituents, including one on the effects of carnosic acid on HL60 and U937 cells (24), and another, on the effects of rosmarinic acid on murine mesangial cells (25). Our study here shows that crude ethanolic rosemary extract has differential anti-proliferative effects on human leukemia and breast carcinoma cells, consistent with the reported growth inhibition by rosmarinic acid from rosemary on murine mesangial cells stimulated with the plateletderived growth factor (PDGF) or TNF $\alpha$ (25). An earlier report showed that carnosic acid, when used alone, is an ineffective inducer of HL60 cell monocyte/macrophage differentiation. Although a direct comparison is not possible, our study here shows that rosemary extract at a non-cytotoxic $1 / 1000$ dilution induced only a small percentage (9\%) of HL60 cell differentiation along the granulocyte lineage compared to the $>85 \%$ induction by the positive control DMF at $100 \mathrm{mM}$, and is thus similar to the marginal induction of HL60 cell differentiation into granulocyte lineage by carnosic acid at 6-7 $\mu \mathrm{M}$, or $2-3 \mu \mathrm{g} / \mathrm{ml}$, as well as the minor effects of the monocyte/macrophage lineage differentiation by carnosic acid alone $(24,26,27)$.

The antioxidant properties of rosemary crude extract and its constituent compounds have been well studied. Most of these reported antioxidant activities are based on cell-free biochemical tests of either crude extract or chemically fractionated constituents of rosemary. In this study, we used the $70 \%$ ethanol extract of rosemary and employed a biochemical assay and a cell-based in vitro assay for testing the antioxidant activities. Data from our biochemical TEAC assay were consistent with the reported hydroxyl radical scavenging antioxidant activity of rosemary and its purified constituents, including carnosic acid, carnosol, rosmarinic acid and ursolic acid, by the DPPH assay (22). The findings are not unexpected since both the TEAC assay and the DPPH assay estimated the hydroxyl radical scavenging effect of the chemicals. Of the two reported studies utilizing cell-based in vitro antioxidant assay, both reports utilized purified constituents of rosemary for the studies. They showed that carnosol, the purified constituent of rosemary, inhibited NO production in LPS-activated murine peritoneal macrophages and RAW 264.7 cells. In contrast, the other constituents of rosemary, carnosic, rosmarinic and ursolic acid, were ineffective $(4,22)$. Lo et al (22) estimated that the IC50 of carnosol was $9.4 \mu \mathrm{M}(3 \mu \mathrm{g} / \mathrm{ml})$ for the inhibition of $\mathrm{NO}$ production in the LPS-activated RAW 264.7 cells, while in our assay a $1 / 1000$ dilution of the rosemary ethanol crude extract, containing $\sim 13.4 \mu \mathrm{g} / \mathrm{ml}$ dry material extracted from rosemary dry leaves, effectively inhibited NO production (76\%) in these cells. Although we cannot make an exact comparison with the reported studies, our data on the rosemary crude extract are in general agreement with the study showing that carnosol inhibited NO production by LPSactivated RAW 264.7 cells.

The inhibition of NO production by LPS-activated RAW 264.7 cells is modulated in part through the inhibition of the iNOS gene expression. The inhibition of iNOS mRNA and protein expression by carnosol at $20 \mu \mathrm{M}$ was effected through the inhibition of the NF-кB activity in these cells (22). RT-PCR data in this study showed that a 1/500 dilution of the rosemary crude extract suppressed, though non-significantly, the iNOS mRNA expression in LPS-activated RAW 264.7 cells. This discrepancy could be due to the higher carnosol dosage of $20 \mu \mathrm{M}(6.7 \mu \mathrm{g} / \mathrm{ml})$, and the longer exposure time of $12 \mathrm{~h}$ in Lo et al's study, compared to the 5-h treatment time in our study.

Many natural polyphenolic compounds with antioxidant activities also have anti-inflammatory activities. Our RT-PCR data on the mRNA expression of the pro-inflammatory cytokines, $\mathrm{TNF} \alpha$ and $\mathrm{IL}-1 \beta$, and the COX-2 enzyme represent additional information on the many biological activities of rosemary.

Despite the many beneficial anti-proliferative, anti-tumorigenic, anti-metastatic, antioxidant and anti-inflammatory activities of rosemary being reported in literature, information is still lacking on the absorption and bioavailability of the active constituents of rosemary in vivo. With its suggested chemopreventive potentials, further studies are needed in order to explore other biological properties of this common spice used by many cultures in the world. It is unknown whether meaningful amounts of the biological active ingredients are present in the daily consumption with the common practice of food preparation. In conclusion, the rosemary ethanol crude extract shows differential anti-proliferative activity in several human tumor cell lines and demonstrates strong antioxidant activity by the TEAC hydroxyl radical scavenging assay. The crude extract also shows antioxidant and anti-inflammatory activities in the inhibition of NO production, and reduction of proinflammatory IL-1B cytokine and COX-2 mRNA expression in LPS-activated RAW 264.7 cells which substantiates its chemopreventive potential.

\section{Acknowledgements}

This study was supported by the Lotte and John Hecht Memorial Foundation. Dr David Hasman of the Forensic Sciences Center, BCIT, performed the HPLC analyses.

\section{References}

1. Okamura N, Haraguchi H, Hashimoto $\mathrm{K}$ and Yagi A: Flavonoids in Rosmarinus officinalis leaves. Phytochemistry 37: 1463-1466, 1994.

2. Angelini LG, Carpanese G, Cioni PL, Morelli T, Macchia M and Flamini G: Essential oils from Mediterranean lamiaceae as weed germination inhibitors. J Agric Food Chem 51: 6158-6164, 2003.

3. Huang MT, Ho CT, Wang ZY, Ferraro T, Lou YR, Stauber K, Ma W, Georgiadis C,Laskin JD and Conney AH: Inhibition of skin tumorigenesis by rosemary and its constituents carnosol and ursolic acid. Cancer Res 54: 701-708, 1994.

4. Chan MM, Ho C and Huang H: Effects of three dietary phytochemicals from tea, ropsemary and rumeric on inflammationinduced nitrite production. Cancer Lett 96: 23-29, 1995.

5. Rababah TM, Hettiarachchy NS and Horax R: Total phenolics and antioxidant activities of fenugreek, green tea, black tea, grape seed, rosemary, guto kola, and ginkgo extracts, vitamin $\mathrm{E}$ and tert-butylhydroquinone. J Agric Food Chem 52: 5183-5186, 2004.

6. Minnunni M, Wolleb U, Mueller O, Pfeifer A and Aeschbacher HU: Natural antioxidants as inhibitors of oxygen species induced mutagenicity. Mutat Res 269: 193-200, 1992.

7. Offord EA, Mace K, Ruffieux C, Malnoe A and Pfeifer AM: Rosemary components inhibit benzo[a]pyrene-induced genotoxicity in human bronchial cells. Carcinogenesis 16: 2057-2062, 1995. 
8. Huang SC, Ho CT, Lin-Shiau SY and Lin JK: Carnosol inhibited the invasion of B16/F10 mouse melanoma cells by suppressing metalloproteinase-9 through down-regulating nuclear factor-kappaB and c-jun. Biochem Pharmacol 69: 221-232, 2005.

9. Singletary K, MacDonald C and Wallig M: Inhibition by rosemary and carnosol of 7,12-dimethylbenz[a] anthracene (DMBA)-induced rat mammary tumorigenesis and in vivo DMBA-DNA adduct formation. Cancer Lett 104: 43-48, 1996.

10. Moran AE, Carothers AM, Weyant MJ, Redston M and Bertagnolli MM: Carnosol inhibits beta-catenin tyrosine phosphorylation and prevents adenoma formation in the C57BL/6J/Min/ ${ }^{+}\left(\mathrm{Min} /{ }^{+}\right)$mouse. Cancer Res 65: 1097-2104, 2005.

11. Plouzek CA, Ciolino HP, Clarke R and Yeh GC: Inhibition of P-glycoprotein activity and reversal of multidrug reisitance in vitro by rosemary extract. Eur J Cancer 35: 1541-1545, 1999

12. Kosaka K and Yokoi T: Carnosic acid, a component of rosemary (Rosmarinus officinalis L.), promotes synthesis of nerve growth factor in T98G human glioblastoma cells. Biol Pharm Bull 26: 1620-1622, 2003.

13. Re R, Pellegrini NA, Proteggente A, Pannela A, Yang M and Rice-Evans C: Antioxidant activity applying an improved ABTS radical cation decolorization assay. Free Radic Biol Med 26: 1231-1237, 1999.

14. Schlesier K, Harwat M, Bohm V and Bitsch R: Assessment of antioxidant activity by using different in vitro methods. Free Radic Res 36: 177-187, 2002.

15. Tai J, Cheung S, Chan E and Hasman D: In vitro studies of Sutherlandia frutescens on human tumor cell lines. J Ethnopharmacol 93: 9-19, 2004

16. Suh N, Luyengi L, Fong HHS, Kingshorn AD and Pezzeto JM: Discovery of natural product chemopreventative agents utilizing HL60 cell differentiation as a model. Anticancer Res 15: 233-240, 1995.

17. Collins RD, Cousar JB, Russell WG and Glick AD: Diagnosis of neoplasm of the immune system. In: Manual of Clinical Immunology. Rose NR and Friedman $\mathrm{H}$ (eds). 2nd edition. American Society for Microbiology, Washington DC, pp98-99, 1980.
18. Wadsworth TL and Koop DR: Effects of wine polyphenolics quercetin and resveratrol on pro-inflammatory cytokine expression in RAW 264.7 macrophages. Biochem Pharmacol 57: 941-949, 1999.

19. Miyamoto M, Hashimoto K, Minagawa K, Satoh K, Komatsu N, Fujimaki M, Nakashima H, Yokote Y, Akahani K, Guputa M, Sarma DNK and Sakagami H: Effect of poly-herbal formula on NO production by LPS-stimulated macrophage-like cells. Anticancer Res 22: 3293-3302, 2002.

20. Bongers M, Leihl E and Barsig J: One-step RT-PCR to detect cytokine/chemokine induction in macrophages. Focus 2: 61-68, 1999.

21. Sun LK, Beck-Schimmer B, Oertli B and Wuthrich RP: Hyaluronan-induced cyclooxygenase- 2 expression promotes thromboxane A2 production by renal cells. Kidney Int 59: 190-196, 2001 .

22. Lo A, Liang Y, Lin-Shiau S, Ho C and Lin J: Carnosol, an antioxidant in rosemary, suppresses inducible nitric oxide synthase through down-regulating nuclear factor-kB in mouse macrophages. Carcinogenesis 23: 983-991, 2002.

23. Singletary KW: Rosemary extract and carnosol stimulate rat liver glutathione-S-transferase and quinone reductase activities. Cancer Lett 100: 139-144, 1996.

24. Steiner M, Priel I, Giat J, Levy J, Sharoni Y and Danilenko M: Carnosic acid inhibits proliferation and augments differentiation of human leukemic cells induced by 1,25-dihydroxyvitamin D3 and retinoic acid. Nutr Cancer 41: 135-44, 2001.

25. Makino T, Ono T, Musa E, Yoshida H, Honda G and Sasayama S Inhibitory effects of rosmarinic acid on the proliferation of cultured murine mesangial cells. Nephrol Dial Transplant 15 $1140-1145,2000$

26. Danilenko $M$, Wang $X$ and Studzinski GP: Carnosic acid and promotion of monocytic differentation of HL60-G cells initiated by other agents. J Natl Cancer Inst 93: 1224-1233, 2001.

27. Danilenko M, Wang Q, Wang X, Levy J, Sharoni Y and Studzinski GP: Carnosic acid potentiates the antioxidant and prodifferentiation effects of 1alpha, 25-dihydroxyvitamin D3 in leukemia cells but does not promote elevation of basal levels of intracellular calcium. Cancer Res 63: 1325-1332, 2003. 